\title{
In vivo analysis of nucleolar proteins modified by the yeast arginine methyltransferase Hmt1/Rmt1p
}

\author{
CHONG XU, PAMELA A. HENRY, AMIT SETYA, and MICHAEL F. HENRY \\ Department of Molecular Biology, University of Medicine and Dentistry of New Jersey, School of Osteopathic Medicine, \\ Stratford, New Jersey 08084, USA
}

\begin{abstract}
In this report, we have investigated the impact of arginine methylation on the Gar1, Nop1, and Nsr1 nucleolar proteins in Saccharomyces cerevisiae. Although previous reports have established that protein arginine methylation is important for nucleocytoplasmic shuttling, they have focused on the examination of heterogeneous nuclear ribonucleoproteins (hnRNPs). We have extended this analysis to several nucleolar proteins that represent a distinct functional class of arginine-methylated proteins. We first developed an in vivo assay to identify proteins methylated by the Hmt1 arginine methyltransferase. This assay is based on the fact that the Hmt1 enzyme utilizes S-Adenosyl-L-methionine as the methyl donor for protein arginine methylation. Following SDS polyacrylamide electrophoresis, 11 distinct proteins were identified as substrates for the Hmt1 methyltransferase. Hmt1p overexpression did not increase the methylation level on these proteins, suggesting they are fully methylated under the conditions examined. Three of the radiolabeled proteins were confirmed to be Gar1p, Nop1p, and Nsr1p. To monitor the cellular localization of these proteins, functional GFP fusion proteins were generated and found to be localized to the nucleolus. This localization was independent of arginine methylation. Furthermore, all three proteins examined did not export to the cytoplasm. In contrast, arginine methylation is required for the export of the nuclear RNA-binding proteins Npl3p, Hrp1p, and Nab2p. The observation that three nucleolar proteins are modified by Hmt1p but are not exported from the nucleolus implies an alternate role for arginine methylation.
\end{abstract}

Keywords: Nop1, Gar1, Nsr1, arginine methylation, posttranslational modification

\section{INTRODUCTION}

Posttranslational protein modification allows the cell to create novel amino acids that serve to expand its polypeptide diversity and function. Although the methylation of protein at arginine residues was first discovered over 30 years ago (Paik and Kim 1968), only more recent experiments have begun to elucidate the physiological importance of this modification. These experiments have been aided by the identification and cloning of arginine methyltransferases from both higher and lower eukaryotic species (Lin et al. 1996; Scott et al. 1998; Tang et al. 1998; Chen et al. 1999; Pollack et al. 1999; Frankel et al. 2002). In addition, the number of potential substrates for these enzymes has grown as genome sequencing projects have revealed numerous proteins containing the RGG motif common to substrates

Reprint requests to: Michael F. Henry, Department of Molecular Biology, UMDNJ-SOM, 2 Medical Center Drive, Stratford, NJ 08084, USA; e-mail: henrymf@umdnj.edu.

Article and publication are at http://www.rnajournal.org/cgi/doi/ 10.1261/rna.5020803. for arginine methylation. Although the impact of arginine methylation on protein function is not yet clear, it has been implicated in a variety of cellular processes ranging from signaling (Altschuler et al. 1999; Bedford et al. 2000; Tang et al. 2000) and transcriptional activation (Chen et al. 1999; Mowen et al. 2001) to nucleocytoplasmic transport (Shen et al. 1998; Yun and Fu 2000).

Two distinct types of protein arginine methyltransferase activities were initially identified in mammalian cell lysates (Ghosh et al. 1988). The two methyltransferases differ in that the Type I enzymes catalyze the formation of asymmetric $\omega-\mathrm{N}^{\mathrm{G}}, \mathrm{N}^{\mathrm{G}}$-dimethylarginine residues whereas Type II enzymes form symmetric $\omega-\mathrm{N}^{\mathrm{G}}, \mathrm{N}^{\prime} \mathrm{G}$-dimethylarginine residues. Mammalian Type I substrates are predominately RNA-binding proteins that include hnRNPA1 and A2 (Kim et al. 1997; Nichols et al. 2000), nucleolin (Lischwe et al. 1985b), poly(A)-binding protein II (Smith et al. 1999), and fibrillarin (Lischwe et al. 1985a). The majority of Type I arginine methylation occurs within a domain referred to as an RGG box. This domain is made up of repeated Gly-Gly dipeptides interspersed with arginines and aromatic residues (Beyer et al. 1977). Myelin basic protein (Baldwin and 
Carnegie 1971), coilin (Hebert et al. 2002), the Sm ribonucleoproteins B/B', D1 and D3 (Brahms et al. 2000, 2001), and the Sm-like protein Lsm4 (Brahms et al. 2001) are the only known substrates for the Type II protein arginine methyltransferases.

The first arginine methyltransferase gene, HMT1 (heterogeneous nuclear ribonucloprotein methyltransferase) was discovered in the yeast Saccharomyces cerevisiae on the basis of its interaction with an abundant yeast mRNA-binding protein termed Npl3p (Henry et al. 1996). The same gene, alternatively called RMT1, was also found in a comprehensive search of the yeast genome for proteins containing methyltransferase domains (Gary et al. 1996). HMT1 is not required for normal cell viability, but is synergistically lethal in at least two genetic backgrounds related to RNA maturation: in strains lacking the $80-\mathrm{kD}$ cap-binding protein gene and strains harboring the temperature-sensitive npl3-1 allele (Henry and Silver 1996; Shen et al. 2000). Furthermore, although sequence comparison does not identify a clear HMT1 homolog in the yeast genome, the fact that a yeast strain disrupted for HMT1 retains 15\% arginine methyltransferase activity leaves open the possibility of a second yeast methyltransferase gene (Gary et al. 1996).

The first two human methyltransferase cDNAs isolated, HRMT1L1/PRMT2 and HRMT1L2/PRMT1, were identified by virtue of their sequence similarity to the yeast arginine methyltransferase (Lin et al. 1996; Scott et al. 1998; Scorilas et al. 2000). Since these initial reports, four additional human arginine methyltransferases (PRMT3-6) have been uncovered utilizing a variety of screens designed to identify proteins involved in different cellular processes (Tang et al. 1998; Chen et al. 1999; Pollack et al. 1999; Frankel et al. 2002). Of these, the only symmetrical arginine methyltransferase is JBP1/PRMT5 (Pollack et al. 1999; Rho et al. 2001). The finding that human HRMT1L2/PRMT2 is a functional homolog of yeast HMT1 indicates that the cellular mechanisms involving arginine methylation are conserved throughout eukaryotes (Scott et al. 1998).

Studies in S. cerevisiae to elucidate the importance of Hmtlp methylation have focused on identifying substrate proteins and examining the impact of arginine methylation on their function. Substrate proteins analyzed thus far have included the nuclear RNA-binding proteins Npl3, Hrp1/ Nab4, Nab2, and Hrb1 (Bossie et al. 1992; Wilson et al. 1994; Henry et al. 1996; Shen et al. 1998). The Npl3 protein has been implicated in silencing (Loo et al. 1995), pre-rRNA processing (Russell and Tollervey 1992; Singleton et al. 1995), and nucleocytoplasmic protein transport (Bossie et al. 1992), and may act as a carrier for poly(A)+ RNA export from the nucleus (Lee et al. 1996). The Hrp1 and Nab2 proteins are both required for efficient mRNA polyadenylation (Kessler et al. 1997; Minvielle-Sebastia et al. 1998), whereas, Hrp1 plays an additional role in the nonsensemediated-decay pathway (Gonzalez et al. 2000). In addition, all of these proteins share the ability to shuttle between the nucleus and the cytoplasm. The first evidence for the importance of HMT1 in cellular processes was the finding that its function is required for the efficient export of the Npl3, Hrp1, and Nab2 proteins from the nucleus (Shen et al. 1998; Green et al. 2002).

To date, arginine methylation studies in S. cerevisiae have been primarily restricted to examining arginine-methylated proteins in the nucleus that play roles in pre-mRNA processing and nuclear export. However, a search of the $S$. cerevisiae genome for candidate methylation substrates suggests that not all arginine-methylated proteins fall into this broad functional class. A number of potential substrates for the Hmt1 methyltransferase are nucleolar proteins implicated in rRNA maturation. These proteins include Garlp, Nop1p, and Nsr1p. Gar1p, which contains 18 RGG repeats, is required for the pseudouridylation of rRNAs (BousquetAntonelli et al. 1997). Nop1 contains 17 RGG repeats and is the yeast homolog to mammalian fibrillarin (Schimmang et al. 1989), whereas Nsr1, the yeast homolog to mammalian Nucleolin, contains 5 RGG repeats and has been linked to $18 \mathrm{~S}$ rRNA processing (Kondo and Inouye 1992; Lee et al. 1992). Although all these nucleolar proteins are likely substrates, no definitive evidence has been presented that these proteins are methylated by the Hmt1 methyltransferase.

To gain a more complete picture of the physiological role of arginine methylation, we examined these potential nucleolar substrate proteins in greater detail. To facilitate our analysis, we first developed an assay to permit the easy identification of arginine-methylated proteins in vivo. With this assay, we demonstrate that all three nucleolar proteins examined in this study are indeed modified by the Hmt 1 enzyme. However, unlike the arginine-methylated nuclear proteins previously examined, they do not shuttle between the nucleus and cytoplasm. The observation that these nucleolar proteins are methylated by Hmt1 but are not exported from the nucleus implies that arginine methylation plays an alternate role for these three proteins.

\section{RESULTS}

\section{The nucleolar proteins, Gar1p, Nop1p, and Nsr1p, are methylated in vitro}

The yeast Hmt1/Rmt1 protein has previously been shown to have methyltransferase activity in vitro, methylating a range of heterogeneous nuclear ribonucleoproteins containing RGG repeats (Gary et al. 1996; Henry and Silver 1996; Shen et al. 1998; Green et al. 2002). However, RGG-containing proteins localized to the nucleolus have not been directly tested as substrates. These potential methyl-accepting substrates include Garlp, Noplp, and Nsr1p (Schimmang et al. 1989; Kondo and Inouye 1992; Lee et al. 1992; BousquetAntonelli et al. 1997). To determine whether these nucleolar proteins were in vitro substrates for the Hmt1 enzyme, each 
protein was fused to either glutathione $S$-transferase (GST) or a 6-histidine tag and expressed in Escherichia coli. The absence of arginine methyltransferase activity in E. coli (Liu and Dreyfuss 1995) allows the use of this bacterium as a source of unmodified yeast protein substrates for in vitro methylation. E. coli extracts containing the recombinant nucleolar proteins were incubated with the radiolabeled methyl donor, S-Adenosyl-L- $\left[\right.$ methyl- $\left.{ }^{3} \mathrm{H}\right]$ methionine $\left({ }^{3} \mathrm{H}\right.$ SAM) in the presence (Fig. 1A, lanes $2,4,6$ ) or absence (Fig. $1 \mathrm{~A}, \mathrm{~B}$, lanes $3,5,7)$ of purified GST-Hmt1 enzyme. The expression and stability of each fusion protein was verified by Western blot analysis of the methylation reactions using either anti-GST or anti-Express antibodies (Fig. 1B, lanes 1-7). Proteins were resolved by SDS-PAGE, and labeling was detected by fluorography.

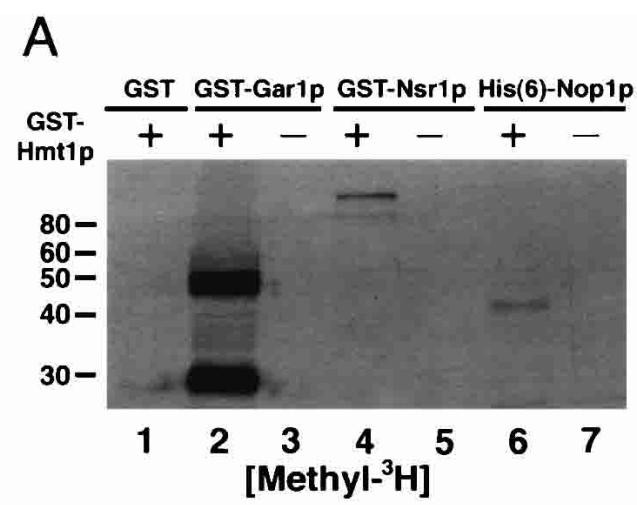

B

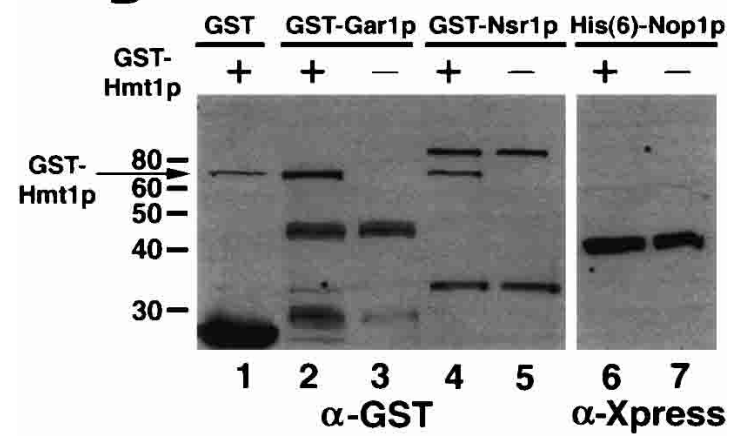

FIGURE 1. Purified Hmtlp methylates Garlp, Noplp, and Nsr1p in vitro. (A) Garlp, Nop1, and Nsr1 are methylated in vitro. E. coli lysates from cells expressing recombinant methyl-acceptor proteins, either GST-Garlp (lanes 2 and 3), GST-Nsrlp (lanes 3 and 4), or His(6)Noplp (lanes 6 and 7), were incubated with S-Adenosyl-L-[methyl$\left.{ }^{3} \mathrm{H}\right]$ methionine ([methyl $\left.\left.-{ }^{3} \mathrm{H}\right] \mathrm{SAM}\right)$ in the presence (lanes 2, 4, and 6) or absence (lanes 3, 5, and 7) of GST-Hmtlp purified from E. coli. As a control, a lysate containing GST alone was incubated in a reaction mixture containing both $\left[\right.$ methyl $\left.{ }^{3} \mathrm{H}\right] \mathrm{SAM}$ and GST-Hmt1p (lane 1). Following incubation, the mixtures were subjected to SDS-PAGE and labeling was detected by fluorography. Sizes are indicated on the left in kilodaltons. (B) Yeast recombinant methyl-acceptor proteins are expressed full length in E. coli. Methyl-accepting proteins present in each of the above methylation reactions were resolved by SDS-PAGE and analyzed by blotting with either monoclonal anti-GST or anti-Xpress antibody. The GST-Hmt1p protein bands (lanes 1, 2, and 4) detected by the anti-GST antibody are indicated with an arrow. Sizes are indicated on the left in kilodaltons.
As shown in Figure 1A, only the recombinant yeast nucleolar fusion proteins present in the E. coli cell extract are radiolabeled (Fig. 1A, lanes 2,4,6). The observed methylation is not due to the presence of either the endogenous E. coli proteins or GST present in the extracts, as cells expressing this tag alone are not labeled (Fig. 1A, lane 1). These results demonstrate that the Gar1, Nop1, and Nsr1 nucleolar proteins are substrates for the Hmtl enzyme in vitro.

\section{Gar1p, Nop1p, and Nsr1p are methylated by Hmt1p in vivo}

To demonstrate that Hmtlp is required for the methylation of Garlp, Noplp, and Nsrlp in living cells, an in vivo arginine methylation assay was developed. The assay is based on the ability of the methyl donor SAM to be efficiently transported across the plasma membrane of yeast (Rouillon et al. 1999) and directly utilized for Hmt1-dependent arginine methylation. To allow detection of methylated proteins, the transferable methyl group on SAM is tritium labeled. As described in Materials and Methods, both wild-type and $\Delta h m t 1$ mutant yeast cells were labeled with ${ }^{3} \mathrm{H}$-SAM, cell extracts were prepared, and proteins were resolved by gel electrophoresis. Methylated proteins were detected by fluorography, and those modified by the Hmt1 methyltransferase were identified as radiolabeled bands present in the wild-type extract but not in the $\Delta h m t 1$ extract. The radiolabeling is due to methylation, not translational incorporation, as the proteins were still labeled in the presence of the translational inhibitor cyclohexamide (Fig. 2, lanes 2,4).

Eleven radiolabeled bands detected in the wild-type extract were not observed in the $\Delta h m t 1$ extract (Fig. 2). These proteins migrated at the following molecular weights: 25.5, $28,36,38,45,58,62,71,75,77$ and $160 \mathrm{kD}$. Assuming that each band represents a single polypeptide, the fact that these proteins were only labeled in the wild-type strain indicates that their methylation is Hmt1 dependent. Furthermore, the absence of any detectable label at the corresponding positions in the $\Delta h m t 1$ strain indicates that Hmtlp is the predominant, if not sole, methyltransferase that modifies these substrates.

Predictably, labeling in the presence of the translational inhibitors cyclohexamide and chloramphenicol reduces the sensitivity of the assay approximately fourfold (Fig. 2, cf. lanes 1,2 and 3,4). However, it also eliminates cotranslational label incorporation, which results in the labeling of at least two additional proteins that migrate at 32 and $46 \mathrm{kD}$ (Fig. 2, lanes 1,3). Importantly, the fact that the number and relative intensity of Hmt1-dependent bands is unchanged in the presence of cyclohexamide indicates that the drug does not alter Hmtlp methylation in vivo. Thus, depending on the application, the assay can be performed with or without cyclohexamide addition. 


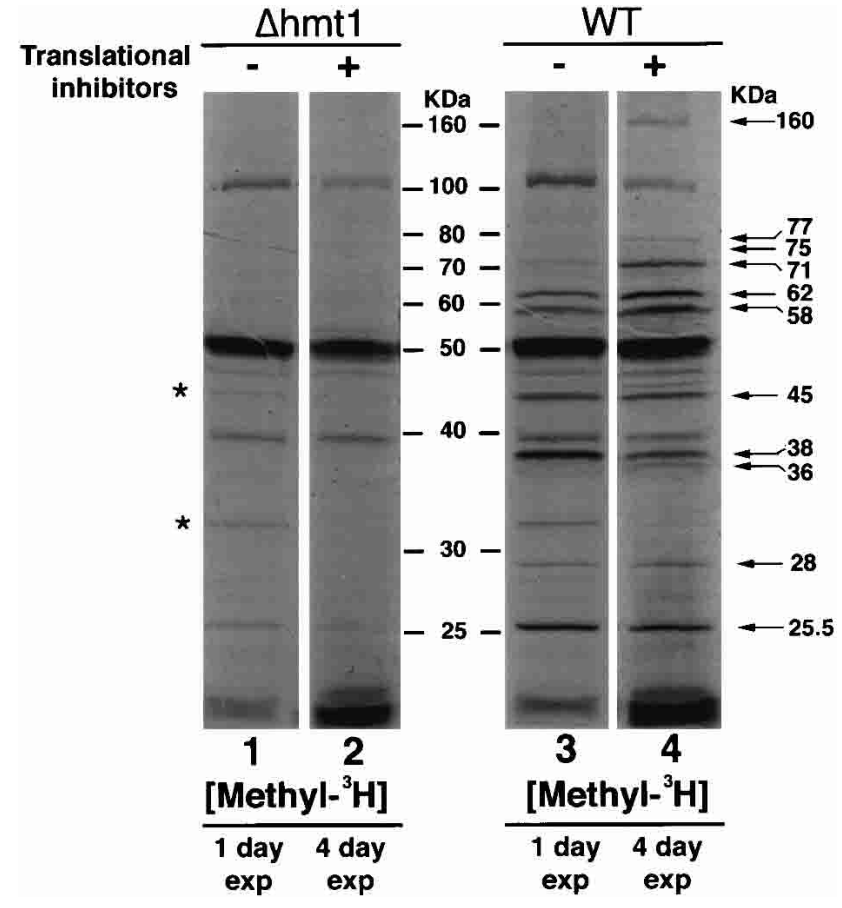

FIGURE 2. The methylation of 11 proteins is Hmtl-dependent in vivo. Wild-type (lanes 3 and 4 ) and $\Delta h m t 1$ cells (lanes 1 and 2) were collected at mid-log phase $(15 \mathrm{~mL})$, then resuspended in $1 \mathrm{~mL}$ synthetic-defined medium and incubated for $10 \mathrm{~min}$ at $30^{\circ} \mathrm{C}$. For lanes 2 and 4 , cells were resuspended in the presence of cycloheximide and chloramphenicol. Labeling was initiated by adding $50 \mu \mathrm{Ci}$ of [methyl$\left.{ }^{3} \mathrm{H}\right] \mathrm{SAM}$ and the cells were incubated at $30^{\circ} \mathrm{C}$ for an additional 90 min. The cells were then lysed and soluble proteins were resolved by SDS-PAGE. Proteins were visualized by Coomassie Blue staining and labeling was detected by fluorography. The 11 bands radiolabeled only in the wild-type extract are denoted with arrows on the right. Protein molecular weights are indicated in kilodaltons in the middle.

We next sought to match the Gar1, Nop1, and Nsr1 proteins to the corresponding radiolabeled bands present in our in vivo methylation assay. Many polypeptides containing RGG domains migrate anomalously "slowly" on a gel; thus, we utilized the observed molecular weight values of these proteins on SDS gels for our comparisons rather than the calculated weights. It has been previously reported that although the Gar1, Nop1, and Nsr1 nucleolar proteins have calculated molecular weights of $21.5,34.5$, and $44.5 \mathrm{kD}$, they migrate aberrantly on a SDS-polyacrylamide gel at 24.5, 38, and $67 \mathrm{kD}$, respectively (Schimmang et al. 1989; Henriquez et al. 1990; Lee et al. 1991; Girard et al. 1992; Lubben et al. 1995). In addition, on some gels, we observed the mobility of the $36-\mathrm{kD}$ methyl-accepting substrate protein to shift closer to the $38-\mathrm{kD}$ band. Based on observed molecular weight values, we speculated that the radiolabeled proteins migrating at approximately $25.5,38$, and 62 $\mathrm{kD}$ on our gels represented the Gar1, Nop1, and Nsr1 proteins, respectively (Fig. 2, WT lanes).

Arginine methylation of the yeast hnRNP, Npl3p, has previously been shown to be Hmtl dependent in vivo
(Henry and Silver 1996). Based upon its reported observed molecular weight, we reasoned that the radiolabeled band migrating at $58 \mathrm{kD}$ represented Npl3p (Fig. 2, WT lanes).

To confirm our protein assignments, we repeated the in vivo methylation assay using cells over expressing Garlp, Nop1p, or Nsr1p. As a control for a substrate known to be methylated in vivo, we also overexpressed the yeast hnRNP protein $\mathrm{Npl} 3$. We reasoned that increased protein expression would result in increased labeling of the corresponding gel band. To allow regulated overexpression, each gene was placed under control of the GAL1 promoter. Transcription from this promoter is induced in the presence of galactose and repressed in the presence of glucose.

Western blot analysis of yeast extracts prepared from cells following $1 \mathrm{~h}$ incubation in galactose confirmed the induction of each protein (Fig. 3A). As expected, overexpression of Garlp, Nop1, Nsr1p, and Npl3p resulted in increased label incorporation of the 25.5-, 38-, 67-, and 58-kD methyl-accepting bands, respectively (Fig. 3B, lanes 3-6). In each case, the intensity of only a single band increased. Thus, our results suggest that the radiolabeled proteins at $25.5,38,58$, and $62 \mathrm{kD}$ represent the Gar1, Nop1, Npl3, and Nsr1 proteins, respectively. Furthermore, the in vivo methylation of these proteins is Hmtl dependent, as they are not labeled in a strain lacking the arginine methyltransferase.

\section{The lack of Hmt1 enzyme activity does not alter the nucleolar localization of Nop1p and Nsr1p}

The steady-state location of Garlp, Noplp, and Nsrlp is predominantly nucleolar as determined by indirect immunofluorescence (Fig. 4, panels C and I; Henriquez et al. 1990; Lee et al. 1991; Girard et al. 1992). We next tested whether the absence of arginine methylation would alter the localization of these nucleolar proteins. The subcellular localization of Noplp and Nsr1p was determined by indirect immunofluorescence utilizing anti-Nop1 and anti-Nsr1 antibodies. In both wild-type and $\Delta h m t 1$ cells, the Nop1 and Nsrl proteins are located in the nucleolus (Fig. 4, panels C, F, I, and L). These results demonstrate that arginine methyltransferase activity is not required for the steady-state nucleolar localization of Noplp and Nsrlp.

To determine the intracellular localization of Garlp, the green fluorescent protein (GFP) was fused to Garlp, and the cellular localization was visualized in both wild-type and $\Delta h m t 1$ strains by directly monitoring the GFP signal. The Gar1-GFP fusion protein localized to the nucleolus in both wild-type and $\Delta h m t 1$ strains (Fig. 5A, panels A,E). This nucleolar accumulation is not due to the presence of the GFP, as GFP alone localizes to the cytoplasm (data not shown). This result is consistent with previous work indicating that the glycine/arginine-rich domains of Garlp are not required for its steady-state accumulation in the nucleolus (Girard et al. 1992). 


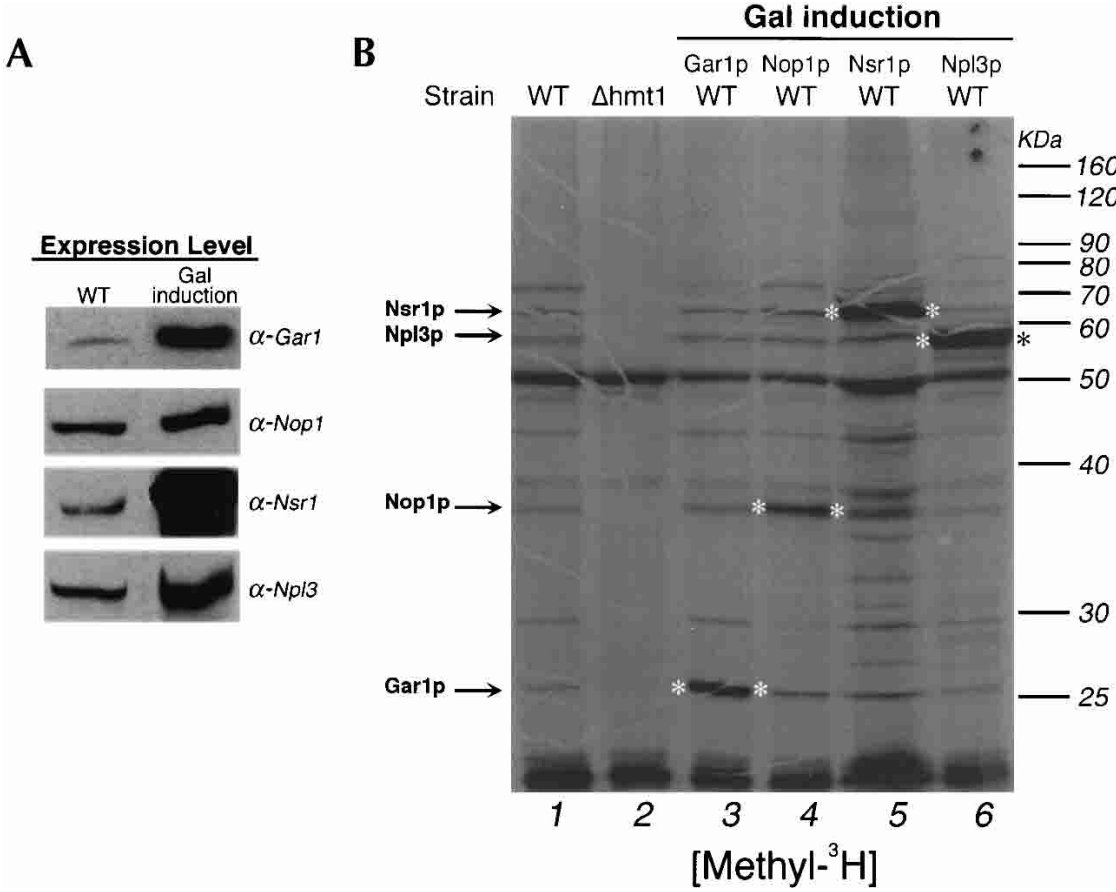

FIGURE 3. The methylation of Garlp, Nop1p, and Nsrlp is Hmt1-dependent in vivo. $(A)$ Galactose induction increases Gar1, Nop1, Nsr1, and Npl3p protein levels. Wild-type cells harboring plasmids encoding either Gar1, Nop1, Nsr1, and Npl3 under control of GAL1 promoter were grown in either glucose or raffinose. Protein expression was induced by adding galactose for $1 \mathrm{~h}$ immediately prior to collection. The cells were concentrated, labeled with [methyl- $\left.{ }^{3} \mathrm{H}\right] \mathrm{SAM}$, lysed, and soluble proteins were resolved by SDS-PAGE and analyzed by immunoblotting with their corresponding antibodies. (B) Induction of methyl-accepting proteins results in an increase in their labeling. Radiolabeled extracts from $A$ were resolved by SDS-PAGE. Proteins were visualized by Coomassie Blue staining, and labeling was detected by fluorography. The migration of the Nsr1, Npl3, Nop1, and Garl proteins are indicated by arrows to the left. Gal-induced proteins are designated with an asterisk on the gel.

\section{Gar1, Nop1, and Nsr1 proteins do not shuttle}

Previous studies have shown that three yeast hnRNPs, Npl3p, Hrplp, and Nab2p, are nucleocytoplasmic shuttling proteins and that their export to the cytoplasm is arginine methylation-dependent (Shen et al. 1998; Green et al. 2002). To test whether Garlp, Nop1p, and Nsrlp were also shuttling proteins, we performed a nuclear export assay utilizing a thermosensitive nucleoporin mutant nup49-313 strain (Lee et al. 1996). At the restrictive temperature, import into the nucleus is blocked, whereas export out of the nucleus is unaffected in this mutant (Doye et al. 1994). In our experiment, plasmids encoding GFP fusions of either the Garl, Nop1, Nsr1, or Npl3 protein under control of the GAL1 promoter were transformed into a nup49-313 $\mathrm{Ts}^{-}$mutant strain. GFP-fusion protein synthesis was induced by galactose, and then repressed by glucose followed by a temperature shift. We then monitored the GFP signal to localize the fusion proteins. If the GFP-nucleolar fusion proteins shuttle, they should accumulate in the cytoplasm of the nup49-313 cells after a shift to $36^{\circ} \mathrm{C}$. Interestingly, whereas the nuclear $\mathrm{Npl} 3$ control protein was cytoplasmic after a temperature shift to

To confirm our indirect immunofluorescence results in living cells, we also generated GFP-Nop1 and GFP-Nsr1 fusion proteins. In agreement with our previous results, both fusion proteins remained nucleolar in a $\Delta h m t 1$ strain (Fig. 5A, panels B,C,F,G). As previously reported (Lee et al. 1996), the steady-state localization of the nuclear control protein, Npl3, remains nuclear (Fig. 5A, panels $\mathrm{D}, \mathrm{H}$ ). In sum, these results indicate that the nucleolar localization of Garlp, Noplp, and Nsrlp is Hmtl independent.

The ability of the nucleolar GFP fusion proteins to functionally replace the equivalent endogenous proteins was tested by transforming each plasmid construct into the corresponding null strains. As shown in Figure 5B, all GFP fusion proteins rescue the loss of the corresponding wildtype genes, indicating they are functional. In each case, the nucleolar-GFP fusion gene was constructed to allow expression from its own promoter. Thus, each fusion protein is functional when expressed at normal cellular levels. Furthermore, the fusion proteins were shown to be expressed full length as determined by immunoblot analysis using anti-GFP antibody (Fig. 5C). Interestingly, the level of Nop1 is significantly higher than Gar1, Nsr1, or Npl3. $36^{\circ} \mathrm{C}$ (Fig. 6, panels $\mathrm{N}$ and $\mathrm{P}$ ), the Gar1, Nop1, and Nsr1 proteins remained in the nucleolus (Fig. 6, panels $\mathrm{B}, \mathrm{D}, \mathrm{F}, \mathrm{H}, \mathrm{J}, \mathrm{L})$, demonstrating that these three nucleolar proteins do not shuttle.

\section{GFP fusion proteins are also methylated in vivo}

Although our results suggest that Garlp, Nop1p, and Nsr1p are methylated by the Hmt1 enzyme and their respective GFP fusion proteins do not shuttle, it is still possible that they do not shuttle simply because the GFP domain blocks methylation of the substrate protein. To eliminate this possibility, we performed the in vivo methylation assay with cells expressing each fusion protein to verify their methylation state. Because we utilized null mutant strains transformed with plasmids encoding the corresponding GFP fusion proteins, we predicted that the matching wild-type protein band would be replaced with a slower migrating fusion protein band.

As expected, a new methyl-accepting protein band was detected in cells expressing GFP-Noplp (Fig. 7, lane 3), 

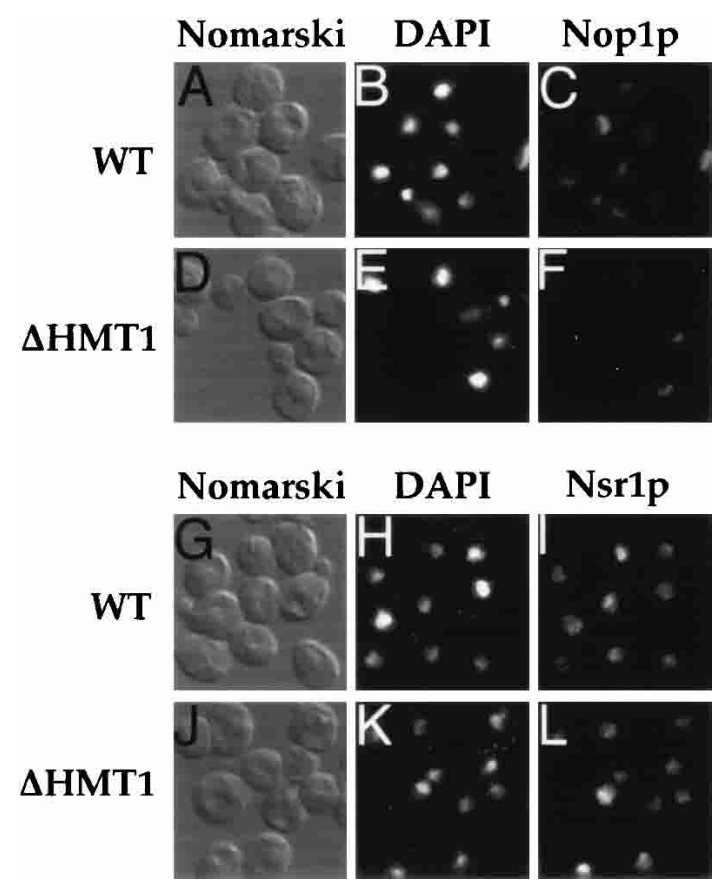

$\Delta$ HMT1
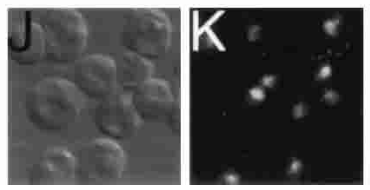

FIGURE 4. Nucleolar localization of Nop1p and Nsr1p does not require arginine methyltransferase activity. Wild-type $(A, B, C, G, H, I)$ and $\Delta h m t 1(D, E, F, J, K, L)$ cells fixed for indirect immunofluorescence were stained with anti-Nop1 $(C, F)$ or anti-Nsr1 $(I, L)$ antibodies and visualized with Alexa Fluor 488-labeled anti-mouse antibody. Cells were viewed by Nomarski optics $(A, D, G, J)$ and nuclei were stained with DAPI $(B, E, H, K)$.

GFP-Nsr1p (Fig. 7, lane 6), and GFP-Npl3p (Fig. 7, lane 4). The observed molecular weights of these proteins closely approximate the predicted size of the Nop1, Nsr1, and Npl3 GFP fusion proteins. Concurrently, the predicted Noplp, Npl3p, and Nsr1p bands (Fig. 7, lanes 3, 4, and 6) were absent in the corresponding deletion strains.

The analysis of $\Delta$ garl cells expressing Gar1-GFP was complicated by the fact that both tagged and untagged Garlp comigrates with the $50-\mathrm{kD}$ and $25.5-\mathrm{kD}$ proteins labeled in the absence of Hmt1 on our in vivo methylation gels (Fig. 7, lanes 2,5). Immunoblot analysis of wild-type cells expressing both Garlp and Garlp-GFP confirms that the untagged and tagged proteins migrate at 25.5 and $50 \mathrm{kD}$, respectively (Fig. 3A, top panel; Fig. 5C, lane 4). The fact that the labeling intensity of the $25.5-\mathrm{kD}$ band is significantly stronger in a wild-type strain than in the $\Delta h m t 1$ strain suggests that the band represents two methyl acceptor proteins, one Hmt1 dependent and the other independent. Furthermore, because the intensity of the $25.5-\mathrm{kD}$ band in the $\Delta$ garl strain drops to a level equal to the $\Delta h m t 1$ strain, we predict that the HMT1 dependent protein is likely Garlp. Unfortunately, because the $50-\mathrm{kD}$ protein is much stronger, this type of comparison cannot be extended to the Gar1-GFP fusion protein. Together, these experimental results indicate that the GFP fusion proteins utilized to detect nucleocytoplasmic shuttling are substrates for arginine methylation.

\section{Gar1p, Nop1p, and Nsr1p are fully methylated in vivo}

The inability of Garlp, Nop1, and Nsr1 to shuttle could conceivably be due to partial methylation of these substrates. To determine whether additional arginine residues could be modified, we examined whether elevated levels of Hmtlp could increase methylation. Figure 8, lanes 1 and 3, shows that when Hmtlp expression is increased during labeling by inducing transcription from the GAL1 promoter, the in vivo methylation of the Gar1, Nop1, and Nsr1 proteins remains unchanged. Western blot analysis showed that Hmtlp levels were increased at least 20-fold following galactose induction (data not shown), and these levels have no phenotypically detectable impact on cell growth. Under these conditions, the level of Npl3 methylation as well as the remaining methyl-accepting substrates remained unchanged. This finding suggests that under the conditions

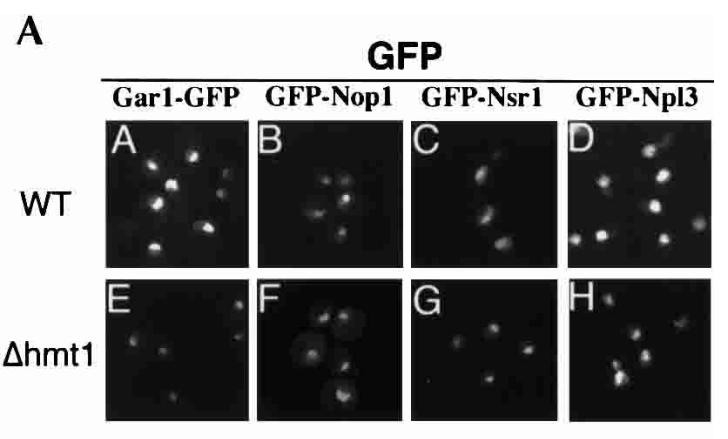

B
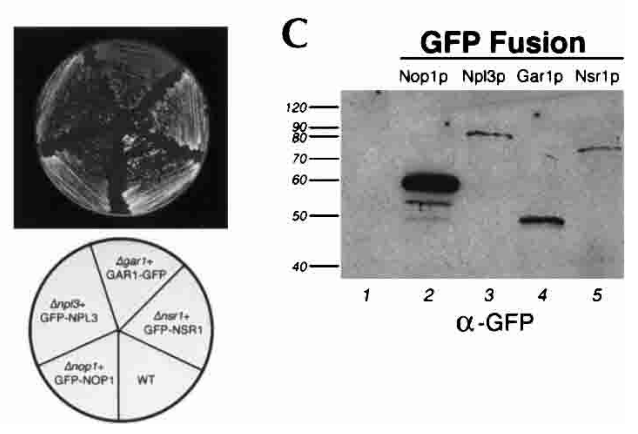

FIGURE 5. The nucleolar GFP fusion proteins function as wild type. (A) Localization of the Gar1, Nop1, Nsr1, and Npl3 fusion proteins is independent of arginine methylation. Cells expressing the GFP fusion proteins in wild-type (upper panels) and $\Delta h m t 1$ (lower panels) background were viewed by direct fluorescence microscopy. (B) The fusion proteins rescue the loss of the corresponding wild-type genes. Plasmids encoding the GFP fusion proteins were transformed into the corresponding null mutant as indicated by the plate schematic. Transformants were restreaked at $30^{\circ} \mathrm{C}$ on SC medium supplemented with glucose. (C) GFP fusion proteins are expressed full length. Protein extracts from yeast cells expressing GFP-Nop1 (lane 2), GFP-Npl3 (lane 3), Gar1-GFP (lane 4), or GFP-Nsr1 (lane 5) were analyzed by Western blot. As a control, extract was also prepared from a wild-type strain not expressing a GFP fusion protein (lane 1). The fusion proteins were detected with a monoclonal anti-GFP antibody. Sizes are indicated on the left in kilodaltons. 


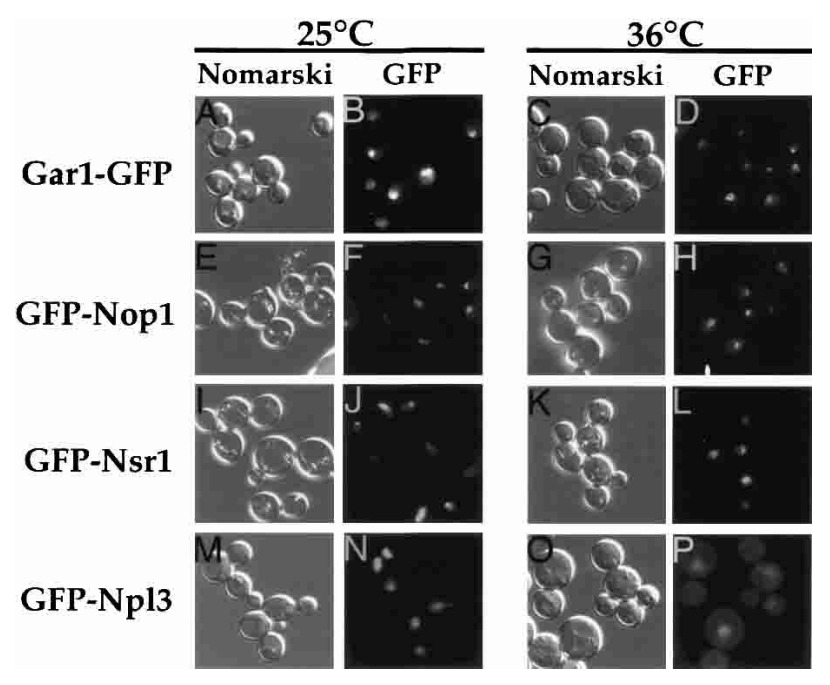

FIGURE 6. Gar1, Nop1, and Nsr1 proteins do not shuttle. nup49-313 $\mathrm{Ts}^{-}$mutant cells carrying reporter plasmids expressing either Gar1GFP $(A-D)$, GFP-Nop1 $(E-H)$, GFP-Nsr1 $(I-L)$, or GFP-Npl3 $(M-P)$ were subjected to the export assay. Cells were incubated for $5 \mathrm{~h}$ at $25^{\circ} \mathrm{C}$ $(A, B, E, F, I, J, M, N)$ or $36^{\circ} \mathrm{C}(C, D, G, H, K, L, O, P)$. Living cells were photographed by Nomarski optics $(A, C, E, G, I, K, M, O)$ or the GFP signal $(B, D, F, H, J, L, N, P)$.

tested, the arginine-methylated proteins detected in our assay are fully modified by the Hmtl enzyme in vivo.

\section{DISCUSSION}

In this report, we have investigated the impact of arginine methylation on the Gar1, Nop1, and Nsr1 nucleolar proteins. We first show that that these RGG-containing proteins are modified in vitro by the yeast arginine methyltransferase, Hmt1/Rmt1. To monitor the methylation of these substrates within the cellular environment, we developed a system to detect Hmt1-dependent methylation in vivo. Using this assay, we have confirmed that the Garl, Nop1, and Nsr1 nucleolar proteins are indeed methylated by Hmtlp within the cell. Previous studies have demonstrated that the nuclear shuttling proteins Npl3, Hrp1/ $\mathrm{Nab} 4$, and Nab2 depend on arginine methylation to exit the nucleus (Shen et al. 1998; Green et al. 2002). In contrast, we have found that although Garlp, Noplp, and Nsrlp are arginine methylated, their cellular function does not include the ability to exit the nucleus. Furthermore, arginine methylation does not alter the localization or stability of these proteins. Taken together, these data suggest that the effect of arginine methylation on substrate function is protein specific.

A biochemical approach was used to provide direct evidence that Hmt1p modifies the Gar1, Nop1, and Nsr1 nucleolar proteins. In a previous report, the Gar1 and Nop1 proteins were inferred to be methyl-accepting substrates (Frankel and Clarke 1999). This tentative identification was based on the observation that the molecular weights and isoelectric points of Garlp and Noplp were similar to proteins modified by recombinant Hmtlp in extracts prepared from Hmt1-deficient cells. In this report, we directly demonstrate that recombinant Hmtlp specifically modifies recombinant Garlp and Noplp, and Nsrlp in vitro, using SAM as the methyl donor. In the GST-Garlp and GSTNsrlp reactions, we were able to standardize enzyme and substrate levels based on Western blot analysis to permit an estimation of relative in vitro methylation levels. Not surprisingly, Gar1, which contains 18 RGG repeats, was methylated at a significantly higher level than Nsr1, which contains only 5 RGG repeats.

Our assay system monitors the predominant argininemethylated proteins in vivo. The assay is based on the fact that ${ }^{3} \mathrm{H}$-SAM is transported across the plasma membrane of S. cerevisiae and directly utilized as the methyl donor to

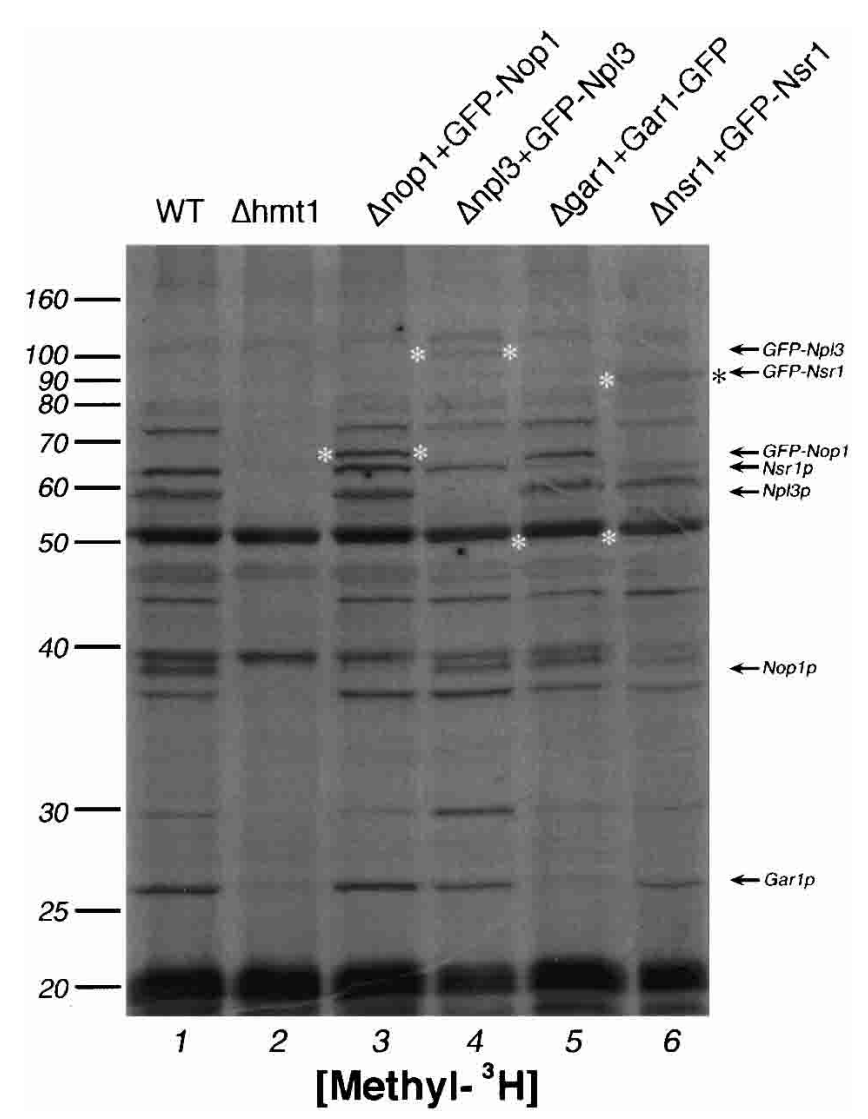

FIGURE 7. GFP fusion proteins are methylated in vivo. Fifteen milliliters of wild-type (lane 1), $\Delta$ hmt1 (lane 2), and null mutant cells harboring corresponding GFP fusion proteins (lanes 3-6) were collected at mid-log phase and resuspended in $1 \mathrm{~mL}$ synthetic-defined medium containing cycloheximide and chloramphenicol. Following a 10 -min incubation at $30^{\circ} \mathrm{C}$, labeling was initiated by adding $50 \mu \mathrm{Ci}$ of [methyl- $\left.{ }^{3} \mathrm{H}\right] \mathrm{SAM}$ and incubation was continued for $90 \mathrm{~min}$. The cells were lysed, and soluble proteins were resolved by SDS-PAGE. Proteins were visualized by Coomassie Blue staining, and labeling was detected by fluorography. Sizes are indicated on the left in kilodaltons. The migration of the GFP fusion proteins are indicated with asterisk on the gel. 


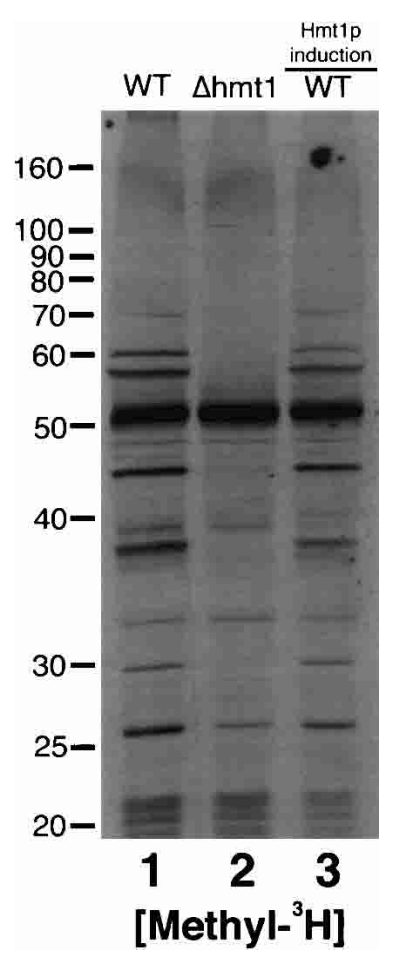

FIGURE 8. Hmtlp-dependent substrate proteins are fully methylated in vivo. Wild-type (lane 1), $\Delta h m t 1$ (lane 2), and wild-type cells transformed with a plasmid carrying HMT1 under control of the GAL1 promoter (lane 3) were grown to mid-log phase in $15 \mathrm{~mL}$ syntheticdefined medium containing raffinose. Induction and labeling were initiated by adding $2 \mathrm{~mL}$ of $20 \%$ galactose and $50 \mu \mathrm{Ci}$ of [methyl${ }^{3} \mathrm{H}$ ]SAM. Following a $90-\mathrm{min}$ incubation at $30^{\circ} \mathrm{C}$, proteins were visualized by Coomassie Blue staining, and labeling was detected by fluorography. Sizes are indicated on the left in kilodaltons.

transfer a radiolabeled methyl group to substrate proteins (Rouillon et al. 1999). Growing yeast cells are labeled with ${ }^{3} \mathrm{H}-\mathrm{SAM}$ and those proteins modified by the Hmt1 methyltransferase are detected in cell lysates as radiolabeled bands that are present on SDS gels in wild-type but not in $\Delta h m t 1$ cells. Our laboratory and others have previously utilized L- $\left[\right.$ methyl $\left.{ }^{3} \mathrm{H}\right]$ methionine as an indirect label for in vivo arginine methylation (Liu and Dreyfuss 1995; Green et al. 2002). However, because this label can be directly incorporated into protein during translation, its use required the addition of translational inhibitors, resulting in reduced methyl incorporation. Furthermore, the potential secondary effects of this inhibitor on arginine methylation had not been fully explored. When labeling with ${ }^{3} \mathrm{H}$-SAM directly, labeling can be extended and sensitivity increased. In this study, we have demonstrated that the labeling of methylarginines is reduced, but otherwise unaffected by the addition of the translational inhibitors cyclohexamide and chloramphenical. For our application, a benefit of this addition is that cotranslational labeling is also inhibited. By this method, we reproducibly detect 11 arginine methylated proteins in S. cerevisiae.

The strategy utilized to confirm the identity of the meth- ylated Nop1, Gar1, Nsr1, and Npl3 proteins on our gel system can easily be extended to identify the seven remaining methyl-acceptor substrate bands. Possible candidates in the yeast database are those RGG-containing proteins whose apparent molecular weights on SDS gels match the methylated species visualized in our assay. Based on these criteria, likely potential methyl-acceptor substrates include the nonessential proteins Gbp2, Hrb1, Psp2, Sbp1, Ski2, and Tif4361, as well as the essential proteins Dbp2, Ded1, Hrp1/ Nab4, and Rps2. Strains lacking these genes are all available as part of the Saccharomyces Genome Deletion Project (Giaever et al. 2002) and would be amenable to analysis in this assay system. Proteins not required for cell viability could be tested directly by assay of the corresponding haploid deletion strain observing loss of a radiolabeled band. Those proteins required for cell viability could be tested by overproduction of the protein in either a wild-type or deletion strain. Prior to this study, the Npl3, Hrp1/Nab4, Hrb1, and Nab2 nuclear proteins have been shown to be arginine methylated in vitro (Henry and Silver 1996; Shen et al. 1998; Green et al. 2002). However, only Npl3p and Nab2p have been shown to be in vivo substrates of Hmtlp (Henry and Silver 1996; Green et al. 2002).

A search of the Saccharomyces genome database (genome-www.stanford.edu) for proteins containing arginine residues in a glycine-rich context yields more than the 11 proteins detected in our assay. In fact, the number of potential candidates increases as the stringency of the search is reduced. How can this excess of potential substrates be reconciled with the limited number of proteins labeled in our in vivo methylation assay? One possibility is that not all proteins containing RGG repeats are methylated in vivo. Although previous studies have roughly defined a recognition consensus sequence consisting of RGG repeats, the consensus is not precise enough to predict all the proteins that receive arginine methylation (Birney et al. 1993; Najbauer et al. 1993; Kim et al. 1997). In fact, we know that even within the context of a single protein not all RGG sequences are modified. For example, only three of four RGG residues within a terminal tryptic peptide of human hnRNPAl were found to be modified (Kim et al. 1997). Another possibility is that the tritium-based assay lacks the sensitivity to detect all the potential methyl-acceptor proteins. Labeling could fall below detection levels if the methyl-accepting substrate was present in low amounts or contained few methylation sites. This appears to be the case for the yeast Hrp1 protein. Although the Hrp1 protein contains four potential sites for arginine methylation within its RGG domains and has previously been shown to be methylated in vitro (Shen et al. 1998), it was not detected on our standard in vivo methylation gels. However, we found Hrp1p could be detected by increasing Hrp1 protein levels (unpubl. results). This was accomplished by either Gal overexpression during labeling or by concentrating the protein following labeling by immunoprecipitation. Thus, the 
sum of these results suggests that the assay may only detect abundant arginine methylated proteins.

Arginine methylation represents but a single class of protein methylation that occurs within the cell (Aletta et al. 1998). Enzymes catalyzing these reactions utilize S-adenosylmethionine and can modify a variety of nucleophilic oxygen, nitrogen, and sulfur atoms on the polypeptide chain. These processes result in methyl esters, methyl amines, methyl amides, and other derivatives on the side chains of 9 of the 20 common amino acids, as well as on several additional residues when present at the amino or carboxyl terminus (Clarke 1993). Given the plethora of protein methyltransferases that utilize SAM as a methyl donor, how do you reconcile the fact that in our system a significant percentage of the methylated proteins detected are HMT1 dependent? One explanation is that those methylated proteins low in abundance or modified at only a few residues would not be detected in our assay. A second explanation is that not all potential protein methylation occurs during our experimental conditions. Finally, as shown by our results, some methylation is cotranslational and is inhibited when labeling is performed in the presence of cyclohexamide.

It has been an open question as to whether Hmtlp is the sole asymmetrical arginine dimethyltransferase in S. cerevisiae. An early experiment suggested the presence of a second enzyme, as a HMT1 disruption strain retained a 15\% level of asymmetric dimethylarginine residues compared to wildtype cells (Gary et al. 1996). However, no clear HMT1 homologs are present in the yeast genome database and, to date, no additional protein with asymmetric dimethylarginine activity has been identified in yeast. The results of our in vivo methylation assay would suggest that for those methyl-accepting substrates only modified in the wild-type strain, Hmtlp is the sole enzyme responsible for their modification. However, it is also possible that some proteins modified in both the wild-type and $\triangle H M T 1$ cells are substrates for a second arginine methyltransferase.

Methylation of the Npl3, Hrp1, and Nab2 shuttling hnRNP proteins facilitates their export from the nucleus, thus implicating this modification in the export of RGGmotif proteins (Shen et al. 1998; Green et al. 2002). In contrast, the characterization of another hnRNP protein, Hrb1, whose export was not affected by methylation, implied that arginine methylation could play an alternate role (Shen et al. 1998). However, this second interpretation was tempered by the possibility that although Hrblp was methylated in vitro, it may not be a bona fide substrate in vivo. In this study, we have expanded the list of known substrates for the Hmt1 methyltransferase to include the nucleolar proteins Garlp, Noplp, and Nsrlp. The idea that arginine methylation affects alternate cellular processes is supported by the results of this study in which three arginine-methylated nucleolar proteins do not shuttle.

The finding that Nsrlp does not shuttle in yeast is interesting in light of the fact that the orthologous protein, nucleolin, shuttles in mammalian cells (Borer et al. 1989). Given that these two proteins are not true homologs, it is reasonable to expect that these proteins could differ in their ability to shuttle. Interestingly, another possible interpretation of this result is that nucleolin shuttling in mammalian cells is independent of arginine methylation. To our knowledge the impact of arginine methylation on nucleolin shuttling has not been tested.

Given that arginine methylation does not impact the localization dynamics of Gar1, Nop1, and Nsr1, future experiments will need to focus on alternate roles for this modification. Likely functions to be modulated include those shared by these three nucleolar proteins: proteinprotein interactions, RNA binding, and snoRNA processing.

\section{MATERIALS AND METHODS}

\section{Strains and Media}

The following yeast strains were used in this study: W303a (MATa ura3-1 leu2-3,112 ade21 his3-11,15 trp11); BY4741 (MATa his3D1 leu2D0 met15D0 ura3D) (Saccharomyces Deletion Project; SDP); \#23710 (MATa/MATa his3D1/his3D1 leu2D0/leu2D0 lys2D0/LYS2 ura3D0/ura3D0 met15D0/MET15 $\Delta$ nop1::KanMX/NOP) (SDP);

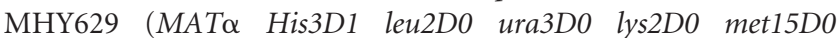
$\Delta$ nop1::KanMX plus pMHY193; \#3171 (MATa his3D1 leu2D0

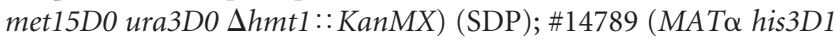
leu2D0 lys2D0 ura3Do $\Delta n s r 1::$ KanMX) (SDP); nup49-313

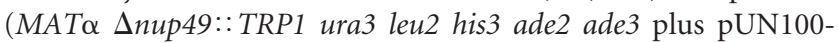

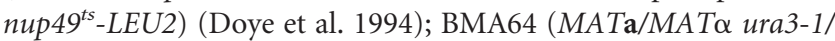
ura3-1 ade2-1/ade2-1 trp1s leu2-3,112/leu2-3,112 his3-11,15/his311,115 can1-100/can1-10) (Baudin-Baillieu et al. 1997); MHY285

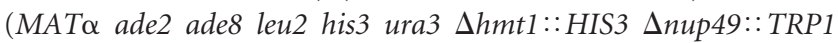
plus nup49-313-LEU2); MHY447 (MATa $\Delta$ hmt1::HIS3 his3 leu2 lys1 ura3 ade2 ade8) and MHY675 (MATa ura3-1 leu2 ade2 ade3 $\Delta n p l 3:: H I S 3$ plus pMHY216). The remaining strains are plasmid transformants. Strains MHY418 (pPS811), MHY479 (pMHY134), MHY481 (pMHY135), and MHY536 (pMHY174) are nup49-313 transformants. Strains MHY419 (pPS811), MHY478 (pMHY134), MHY480 (pMHY135), and MHY541 (pMHY174) are MHY285 transformants. Strains MHY805 (pMHY194), MHY806 (pMHY193), MHY807 (pMHY207), and MHY829 (pMHY216) are \#3171 transformants. Strains MHY769 (pMHY229), MHY770 (pMHY230), MHY771 (pMHY231), MHY813 (pPS426), and MHY822 (pMHY260) are BY4741 transformants. Strain MHY800 (pMHY194) is a transformant of \#14789.

Strain MHY686, $\Delta$ gar1::TRP1, was constructed as follows: A PCR strategy (Baudin-Baillieu et al. 1997) was used to produce a DNA fragment in which TRP1 is flanked by the $5^{\prime}$ and $3^{\prime}$ sequences of GAR1. This fragment was amplified from pUC19-TRP1 with the hybrid primers 5' TGAR1 and 3' TGAR1. Following amplification, the reaction mixture was directly transformed into strain BMA64 to disrupt one copy of the genomic GAR1. Transformants were confirmed by PCR to have the appropriate disrupted as well as wild-type GAR1 genes. To create the nup49-313 $\Delta h m t 1$ double mutant (MHY285), nup49-313 was mated to strain MHY447, a strain created exactly as described for PSY865 (Henry 
and Silver 1996). Standard yeast genetic methods and selective growth media were as described previously (Henry et al. 1996).

\section{Plasmid constructs}

All plasmids and primers used in this study are summarized in Table 1. A series of plasmids was constructed to facilitate the analysis of each nucleolar protein. Each set consists of a yeast centromere plasmid harboring (1) the wild-type allele, (2) the same allele fused to the GFP gene under control of its own promoter or (3) that of GAL1, and (4) an E. coli expression vector encoding the wild-type allele fused to either GST or His(6).

The GAR1 set of plasmids was constructed as follows. The GAR1 gene was PCR amplified from yeast genomic DNA using primers Gar1 5'/Gar1 3' and the EcoRI/SalI digested product was inserted into pRS316 to yield pMHY122. To generate $\mathrm{P}_{\mathrm{GAL} 1}$ GAR1-GFP (pMHY134), the GAR1 ORF was amplified from pMHY122 with primers 5' Gar-Spe /3' Gar-Xho (to simultaneously introduce a SpeI site 2 bp upstream of the start codon and replace the stop codon with a XhoI site) and the SpeI/XhoI-digested product was then inserted into the $\mathrm{XbaI} / \mathrm{XhoI}$ sites of pMHY68. To construct $\mathrm{P}_{\text {GAR1 }}$ GAR1-GFP (pMHY207), a PshA1-Sal1 fragment encoding the GAR1 C terminus was excised from pMHY122 and replaced with a PshAI-NsiI fragment encoding the GAR1-GFP C terminus from pMHY134. The SalI and NsiI sites were blunted to allow ligation. To construct $\mathrm{P}_{G A L 1}$ GAR1 (pMHY229), GAR1 was PCR amplified from pMHY122 with primers Bam-GAR1/GAR1 3'HindIII and then the BamH1/HindIII-digested product was inserted into pPS311. To generate GST-GAR1 (pMHY176) the GAR1 ORF was PCR amplified from pMHY134 with primers BamGAR1/3' Gar1-EcoRI and the BamHI/EcoRI-digested product was inserted into pGEX-4T-1 (Amersham Biosciences).

The NOP1 set of plasmids was constructed as follows. The NOP1 gene was PCR amplified from genomic DNA using primers Nop1 5'/Nop1 $3^{\prime}$ and the EcoRI/SacI-digested product was inserted into pRS316 to yield pMHY123. To generate $\mathrm{P}_{G A L}$ GFPNOP1 (pMHY135), the NOP1 gene was amplified from pMHY123 using primers Bam-NOP1/NOP1-HindIII (to introduce a BamHI site immediately upstream of the NOP1 start codon and a HindIII site downstream from its stop codon) and inserting the BamHI/ HindIII-digested product into pCGF-1A. As a first step to generate $\mathrm{P}_{\text {NOP1 }}$ GFP-NOP1 (pMHY193), an NheI site was introduced immediately after the ATG codon (pMHY185) by inserting two PCR products (from pMHY123) encoding flanking sequences at a common NheI site into the EcoRI/HindIII sites of pRS316. The primer combinations used were Nop-Nhe \#1/NOP1-HindIII and NopNhe \#2/pRS316 MCS. DNA encoding GFP and the N terminus of Nop1p was PCR amplified from pMHY135 with primers GFPNheI/Nop1 600 and the NheI/BglII-digested product was swapped into the NheI/BglII sites of pMHY185 to yield pMHY193. To construct $\mathrm{P}_{\text {GAL1 }}$ NOP1 (pMHY230), NOP1 was PCR amplified from pMHY123 with primers Bam-NOPI/NOPI-HindIII and the BamH1/HindIII-digested product encoding the entire ORF of NOP1 was inserted into pPS311. This same product was inserted into pRSET-B to generate a His(6)-NOP1 fusion gene.

The NSR1 series of plasmids was constructed as follows. A fragment encoding the NSR1 gene was PCR amplified from genomic DNA using primers Nsr1 $5^{\prime}$ \#2/Nsr1 3' \#2. The SpeI/HindIIIdigested product was then inserted into pRS316 to generate pMHY139. To generate $\mathrm{P}_{\text {GAL1 }}$ GFP-NSR1 (pMHY174), the NSR1 gene was amplified from pMHY139 (with primers 5' NSR1 BamHI and $3^{\prime}$ NSR1-HindIII) and the BamHI/HindIII-digested PCR product was inserted into pCGF-1A. To construct $\mathrm{P}_{N S R 1}$ GFP-NSR1 (pMHY194), an NheI site was first introduced at the GFP start codon by inserting two PCR products encoding flanking sequences at a common NheI site into the SpeI/HindIII sites of pRS315 (pMHY186). The Nsr1-Nhe \#1/pRS316 MCS and Nsr1Nhe \#2/Nsr-SpeI primer combinations were used. A fragment encoding GFP and the $\mathrm{N}$ terminus of Nsrlp was amplified from pMHY174 with primers GFP-NheI and Nsr1-800. The resulting NheI/BglII-digested PCR product was swapped into plasmid pMHY186 to yield pMHY194. To construct $\mathrm{P}_{\text {GAL1 }}$ NSR1 (pMHY231), NSR1 was amplified from pMHY139 (with primers $5^{\prime}$ NSR1 BamHI and $3^{\prime}$ Nsr1 HindIII) and the BamH1/HindIIIdigested product was inserted into pPS311. To generate a GSTNSR1 fusion (pMHY178), the NSR1 ORF was amplified from pMHY174 (with primers 5' NSR1 BamHI and 3' Nsr1 SmaI) and inserting the BamHI/SmaI-digested product into pGEX-4T-1 (Amersham Biosciences).

A $\mathrm{P}_{N P L 3}$ GFP-NPL3 plasmid was constructed as follows. The unique pRS316 vector $K p n I$ site was eliminated by $K p n I$ digestion followed by blunt end formation and religation to yield pMHY199. A NheI site was then introduced immediately after the ATG codon of the NPL3 ORF by ligating two PCR products (from pMHY3) encoding flanking sequences at a common NheI site and inserting them into the SacI/SmaI sites of pRS316 to yield pMHY203. The primer combinations used were Npl3-Nhe \#1/ Npl3-ScaI and Npl3-Nhe \#2/Npl3-Sac. A fragment encoding GFP and the $\mathrm{N}$ terminus of Npl3p was amplified from pPS811 with primers GFP-NheI and NPL3-KpnI. The resulting PCR product was digested with NheI/KpnI and swapped into plasmid pMHY203 to yield pMHY216.

\section{In vitro methylation reaction}

Recombinant GST-Hmtlp $(0.2 \mu \mathrm{g})$ expressed and purified from $E$. coli (Henry and Silver 1996) was incubated with $3 \mu \mathrm{L}{ }^{3} \mathrm{H}-\mathrm{SAM}$ (specific activity of $84 \mathrm{mCi} / \mathrm{mmol}$; Amersham Biosciences) and $E$. coli whole-cell extracts in a $15-\mu \mathrm{L}$ volume of methylation assay buffer (50 mM Na-MOPS buffer at pH 7.2, 2 mM EDTA, 0.3 M $\mathrm{NaCl}, 0.1 \mu \mathrm{g}$ each of the following protease inhibitors per milliliter: aprotinin, chymostain, leupeptin, and pepstain) for $40 \mathrm{~min}$ at $30^{\circ} \mathrm{C}$. For GST-Gar1 and GST-Nsr1, the amount of extract added to each reaction was adjusted to give equal amounts of recombinant fusion protein, $30 \mu \mathrm{g}$ and $5 \mu \mathrm{g}$, respectively. For His(6)Nop1, a whole-cell lysate was first precipitated with 55\% ammonium sulfate and $20 \mu \mathrm{g}$ extract was added to each reaction. Terminated reactions were loaded onto a $13 \%$ SDS polyacrylamide gel. Following electrophoresis, the gel was fluorographed, dried, and exposed to preflashed HyperFilm (Amersham Biosciences) at $-80^{\circ} \mathrm{C}$ for $12-24 \mathrm{~h}$.

\section{In vivo methylation assay}

Cells were grown to $1 \times 10^{7}$ cells per milliliter at $30^{\circ} \mathrm{C}$ in syntheticdefined media supplemented with either leucine, uracil if plasmid selection was required, or both, and $2 \%$ glucose. Cells $\left(1.5 \times 10^{8}\right)$ were collected by centrifugation, washed once in sterile $\mathrm{H}_{2} \mathrm{O}$, and resuspended in $950 \mu \mathrm{L}$ of the same media containing $40.0 \mu \mathrm{L} 250$ 
TABLE 1. Plasmids and primers used in this study

\begin{tabular}{|c|c|c|}
\hline Plasmid/primer & Description & Source \\
\hline pRS315 & yeast centromere shuttle vector $L E U 2$ & Sikorski \& Hieter 1989 \\
\hline pRS316 & yeast centromere shuttle vector URA3 & Sikorski \& Hieter 1989 \\
\hline pUC19-TRP1 & E. coli cloning vector carrying TRP1 & $\begin{array}{l}\text { Baudin-Baillieu et al. } \\
1997\end{array}$ \\
\hline pGEX4T-1 & E. coli GST expression vector & Amersham Biosciences \\
\hline pRSET B & E. coli His(6) tag expression vector & Invitrogen, Inc. \\
\hline pPS311 & yeast centromere GAL1 promoter expression vector $L E U 2$ & Flach et al. 1994 \\
\hline pPS426 & yeast centromere galactose inducible expression $L E U 2$ vector containing NPL3 & Flach et al. 1994 \\
\hline pCGF-1A & $\begin{array}{l}\text { yeast high-copy galactose inducible expression vector for fusion to the carboxyl terminus } \\
\text { of GFP }\end{array}$ & Kahana and Silver 1996 \\
\hline pGAL-HMT1 & 0.6-kb BamHI-Xbal HMT1 fragment in pPS311 & Henry and Silver 1996 \\
\hline pMHY3 & 3.8-kb chromosomal fragment containing NPL3 in Ycp50 & Henry et al. 1996 \\
\hline pMHY68 & yeast high-copy GAL1 promoter expression vector carrying FGF-GFP & $\begin{array}{l}\text { P. Henry and M. Henry } \\
\text { (unpubl. plasmid) }\end{array}$ \\
\hline pMHY122 & 1.9-kb EcoRI-Sall chromosomal fragment containing GAR1 in pRS316 & This study \\
\hline pMHY123 & 2.3-kb EcoRI-Sall chromosomal fragment containing NOP1 in pRS316 & This study \\
\hline pMHY134 & 620-bp Spel-Xhol fragment containing GAR1 ORF replacing FGF in pMHY68 & This study \\
\hline pMHY135 & 1.6-kb BamH1-HindIII fragment containing NOP1 in pCGF-1A & This study \\
\hline pMHY139 & 2.3-kb Spel-HindIII chromosomal fragment containing NSR1 in pRS316 & This study \\
\hline pMHY174 & 1.6-kb BamH1-HindIII fragment containing NSR1 in pCGF-1A & This study \\
\hline pMHY176 & 1-kb BamHI-EcoRI fragment containing GAR1 in pGEX4T-1 & This study \\
\hline pMHY178 & 1.6-kb Smal-BamHI fragment containing NSR1 in pGEX4T-1 & This study \\
\hline pMHY180 & 1.6-kb Bg/ll-HindIII fragment containing NOP1 in pRSET B & This study \\
\hline pMHY185 & pMHY123 with Nhel site at NOP1 start codon & This study \\
\hline pMHY186 & pRS315 carrying NSR1 with Nhel site at start codon & This study \\
\hline pMHY193 & GFP-NOP1 under control of the NOP1 promoter in pRS316 & This study \\
\hline pMHY194 & GFP-NSR1 under control of the NSR1 promoter in pRS315 & This study \\
\hline pMHY2O3 & pMHY3 with Nhel site at NPL3 start codon & This study \\
\hline pMHY207 & GAR1-GFP under control of the GAR1 promoter in pRS316 & This study \\
\hline pMHY216 & GFP-NPL3 under control of the NPL3 promoter in Ycp50 & This study \\
\hline pMHY229 & 1.1-kb BamHI-HindIII GAR1 fragment in pPS311 & This study \\
\hline pMHY230 & 1.5-kb BamHI-HindIII NOP1 fragment in pPS311 & This study \\
\hline pMHY231 & 1.5-kb BamHI-HindIII NSR1 fragment in pPS311 & This study \\
\hline Gar1 5' & GCATCAAGCTCAGGATCCGT & This study \\
\hline Gar1 3' & GTCGGTCATGGTAGACCAAC & This study \\
\hline Nop1 5' & GAGCTAGCACTGTGCСАTCT & This study \\
\hline Nop1 3' & GTCTGTCTGGGTACAACCTC & This study \\
\hline 5' Gar-Spe & TTCСTTCСACTAGTTAATGAGTTTCAGAGGAGGT & This study \\
\hline 3' Gar-Xho & ССТTСТTСТСGАGАТСТTСТАССТССТСТGАААСС & This study \\
\hline Bam-GAR1 & AAGTAGGAAGGATCCATGAGTTTCAGAGGAGGTAATAGAGGTG & This study \\
\hline GAR1 3'-HindIII & CGCAAGCTTGGTCGACAAGTTATCACC & This study \\
\hline Nop1 5' & GAGCTAGCACTGTGCСАTCT & This study \\
\hline Nop1 3' & GTCTGTCTGGGTACAACCTC & This study \\
\hline Bam-NOP1 & ACCCACCAAGGATCCATGTCATTCAGACCAGGTAGCAGAG & This study \\
\hline NOP1-HindIII & AACCACCACAAGCTTCCAATCAACGCAACACACGCTC & This study \\
\hline pRS316 MCS & GTTGTGTGGAATTGTGAGCG & This study \\
\hline Nop-Nhe \#2 & CAGAGCTAGCCATTACTGTTTTAGTTGATTTGAG & This study \\
\hline Nop-Nhe \#1 & AGGAATGGCTAGCAGACCAGGTAGCAGAGGTG & This study \\
\hline GFP-Nhel & GGAATGGCTAGCAAAGGAGAAGAACTCTTCACTGG & This study \\
\hline Nop1 600 & ААTTCTCTGCСTGGTCTGTG & This study \\
\hline Nsr1 5' \#2 & CСTCATACGCAGAGACAGTG & This study \\
\hline Nsr1 3' \#2 & CTGATAACACCTTAATGTGAGTA & This study \\
\hline 5' NSR1 BamHI & AAGTAGGAAGGATCCATGGTCAAGACTACTAAAGTAAA & This study \\
\hline 3' NSR1 HindIII & GCACAACGCCCAAGCTTTTA & This study \\
\hline Nsr-Spel & AAGGACTAGTATTTAAACCCCATCACGTTGGATTG & This study \\
\hline Nsr1-Nhe \#2 & GTTGGCTAGCCATCTTATTTTAATCCTGCC & This study \\
\hline Nsr1-Nhe \#1 & AGGATGGCTAGCACTTACTAAAGTAAAAGGTAACAAG & This study \\
\hline Nsr1 800 & GTGTCAGATGGTTCAGATGGG & This study \\
\hline Npl3-Sac & CGСТCСАСАAАTCCACGTC & This study \\
\hline Npl3-Nhe \#2 & GTTGGCTAGCCATTATCCTTATGGTTTTAGC & This study \\
\hline
\end{tabular}


TABLE 1. Continued

\begin{tabular}{llc}
\hline Plasmid/primer & \multicolumn{1}{c}{ Description } & Source \\
\hline Npl3-Nhe \#1 & AGGATGGCTAGCTCTGAAGCTCAAGAAACTCACG & This study \\
Npl3-Scal & CACAGATTTAACAGGCCATAATAGTAC & This study \\
NPL3-Kpnl & CTTCTGATTGGTGGAGGATTG & This study \\
5' TGAR1 & CCAAAAGATCACCTGAGGATAATTTTTAACCAAAAGAA & This study \\
3' TGAR1 & GATAAAGGATGGTTTTTTTTTTATTTTTTTCTAGCTAG & This study \\
3'Gar1 EcoRI & CGGAATTCGTCGACAAGTTATCACCCTAC & This study \\
3'Nsr1 Smal & TCCCCCGGGGCACAACGCCCAAGCTTTTA & This study \\
\hline
\end{tabular}

$\mathrm{mM}$ potassium phthalate buffer $(\mathrm{pH}$ 5.0). When required, translational inhibitors were added to the resuspended cells at the following amounts: $15 \mu \mathrm{g}$ each of cycloheximide and chloramphenicol. Cells were immediately transferred to $12 \times 75 \mathrm{~mm}$ culture tubes and incubated for $10 \mathrm{~min}$ at $30^{\circ} \mathrm{C}$ on a rolling drum. Labeling was initiated by the addition of $50.0 \mu \mathrm{Ci}$ of ${ }^{3} \mathrm{H}$-SAM (specific activity of $84 \mathrm{mCi} / \mathrm{mmol}$; Amersham Biosciences) and incubation was continued for $90 \mathrm{~min}$ at $30^{\circ} \mathrm{C}$. Cells were then pelleted, washed once in lysis buffer $(25 \mathrm{mM}$ Tris- $\mathrm{HCl}, 1 \mathrm{mM}$ sodium EDTA, $1 \mathrm{mM}$ sodium EGTA at pH 7.5), and resuspended in 100 $\mu \mathrm{L}$ of lysis buffer supplemented with protease inhibitors $(10 \mathrm{mg} /$ $\mathrm{mL}$ phenylmethylsulfonyl fluoride and $2.5 \mu \mathrm{g} / \mathrm{mL}$ [final] each of aprotinin, leupeptin, chymostatin, and pepstatin) and $1 \mathrm{M} \mathrm{DTT}$. Cells were lysed and protein extracts clarified by a 10 -min centrifugation at 13,000 r.p.m. at $4^{\circ} \mathrm{C}$. Proteins were then resolved by SDS-PAGE and analyzed via Coomassie staining, fluorography, and immunoblot analysis.

\section{Immunoblot analysis}

Total cell extracts were prepared (Bossie et al. 1992) from cells grown in either YEPD or SC medium. Proteins were resolved by SDS-PAGE, transferred, and immunoblotted as described previously (Bossie et al. 1992). Rabbit polyclonal anti-Garlp and affinity purified anti-Npl3p (Bossie et al. 1992) were used at 1:200 and 1:1000, respectively. Mouse monoclonal anti-GFP (Clontech), anti-GST B-14 (Santa Cruz Biotechnology), anti-Nop1 A66 (Henriquez et al. 1990), and anti-Nsr1 5B5 antibodies were used at concentrations of $1: 1000,1: 5000,1: 10,000$ and 1:5000, respectively. The blots were then incubated with horseradish peroxidase (HRP)-conjugated anti-mouse antibodies at a concentration of 1:5000 and detected with ECL Western Blotting Reagents (Amersham Biosciences).

\section{Export assay}

The nuclear export assay was performed exactly as described (Lee et al. 1996). Briefly, cells containing various reporter plasmids are induced for $2 \mathrm{~h}$ in medium containing galactose to express the reporter followed by repression for $2 \mathrm{~h}$ in medium containing glucose. Cells are then incubated for $5 \mathrm{~h}$ at either $25^{\circ} \mathrm{C}$ or $36^{\circ} \mathrm{C}$ and examined for GFP fluorescence.

\section{Indirect immunofluorescence}

Indirect immunofluorescence microscopy was performed as previously described (Sadler et al. 1989). Mouse monoclonal anti-
Nop1p A66 (Henriquez et al. 1990) was used at 1:2000, and mouse monoclonal 5B5 anti-Nsr1p was used at 1:2000.

\section{ACKNOWLEDGMENTS}

We are grateful to Dr. Agnès Baudin-Baillieu for the TRP1 knockout plasmid and strain, Dr. John Aris for anti-Nop1, Dr. Michèle Caizergues-Ferrer for anti-Gar1, and Dr. John Kilmartin for antiNsr1. We thank the members of the Henry laboratory for critical reading of the manuscript and Judith Franco and Yi Wei for their technical assistance. This work was supported by a grant from the National Institutes of Health (GM58493) to M.F.H.

The publication costs of this article were defrayed in part by payment of page charges. This article must therefore be hereby marked "advertisement" in accordance with 18 USC section 1734 solely to indicate this fact.

Received January 2, 2003; accepted March 11, 2003.

\section{REFERENCES}

Aletta, J.M., Cimato, T.R., and Ettinger, M.J. 1998. Protein methylation: A signal event in post-translational modification. Trends Biochem. Sci. 23: 89-91.

Altschuler, L., Wook, J.O., Gurari, D., Chebath, J., and Revel, M. 1999. Involvement of receptor-bound protein methyltransferase PRMT1 in antiviral and antiproliferative effects of type I interferons. $J$. Interferon Cytokine Res. 19: 189-195.

Baldwin, G.S. and Carnegie, P.R. 1971. Specific enzymic methylation of an arginine in the experimental allergic encephalomyelitis protein from human myelin. Science 171: 579-581.

Baudin-Baillieu, A., Guillemet, E., Cullin, C., and Lacrout, F. 1997. Construction of a yeast strain deleted for the TRP1 promoter and coding region that enhances the efficiency of the polymerase chain reaction-disruption method. Yeast 13: 353-356.

Bedford, M.T., Frankel, A., Yaffe, M.B., Clarke, S., Leder, P., and Richard, S. 2000. Arginine methylation inhibits the binding of proline-rich ligands to Src homology 3, but not WW, domains. J. Biol. Chem. 275: 16030-16036.

Beyer, A.L., Christensen, M.E., Walker, B.W., and LeStourgeon, W.M. 1977. Identification and characterization of the packaging proteins of core 40S hnRNP particles. Cell 11: 127-138.

Birney, E., Kumar, S., and Krainer, A.R. 1993. Analysis of the RNArecognition motif and RS and RGG domains: Conservation in metazoan pre-mRNA splicing factors. Nucleic Acids Res. 21: 5803-5816.

Borer, R.A., Lehner, C.F., Eppenberger, H.M., and Nigg, E.A. 1989. Major nucleolar proteins shuttle between nucleus and cytoplasm. Cell 56: 379-390.

Bossie, M.A., DeHoratius, C., Barcelo, G., and Silver, P. 1992. A mutant nuclear protein with similarity to RNA binding proteins in- 
terferes with nuclear import in yeast. Mol. Biol. Cell 3: 875-893.

Bousquet-Antonelli, C., Henry, Y., G'Elugne, J.P., Caizergues-Ferrer, M., and Kiss, T. 1997. A small nucleolar RNP protein is required for pseudouridylation of eukaryotic ribosomal RNAs. EMBO J. 16: 4770-4776.

Brahms, H., Raymackers, J., Union, A., de Keyser, F., Meheus, L, and Luhrmann, R. 2000. The C-terminal RG dipeptide repeats of the spliceosomal Sm proteins D1 and D3 contain symmetrical dimethylarginines, which form a major B-cell epitope for anti-Sm autoantibodies. J. Biol. Chem. 275: 17122-17129.

Brahms, H., Meheus, L., de Brabandere, V., Fischer, U., and Luhrmann, R. 2001. Symmetrical dimethylation of arginine residues in spliceosomal Sm protein B/B' and the Sm-like protein Lsm4, and their interaction with the SMN protein. RNA 7: 1531-1542.

Chen, D., Ma, H., Hong, H., Koh, S.S., Huang, S.M., Schurter, B.T., Aswad, D.W., and Stallcup, M.R. 1999. Regulation of transcription by a protein methyltransferase. Science 284: 2174-2177.

Clarke S. 1993. Protein methylation. Curr. Opin. Cell. Biol. 5: 977-983.

Doye, V., Wepf, R., and Hurt, E.C. 1994. A novel nuclear pore protein Nup133p with distinct roles in poly(A)+ RNA transport and nuclear pore distribution. EMBO J. 13: 6062-6075.

Flach, J., Bossie, M., Vogel, J., Corbett, A., Jinks, T., Willins, D.A., and Silver, P.A. 1994. A yeast RNA-binding protein shuttles between the nucleus and the cytoplasm. Mol. Cell. Biol. 14: 8399-8407.

Frankel, A. and Clarke, S. 1999. RNase treatment of yeast and mammalian cell extracts affects in vitro substrate methylation by type I protein arginine N-methyltransferases. Biochem. Biophys. Res. Commun. 259: 391-400.

Frankel, A., Yadav, N., Lee, J., Branscombe, T.L., Clarke, S., and Bedford, M.T. 2002. The novel human protein arginine N-methyltransferase PRMT6 is a nuclear enzyme displaying unique substrate specificity. J. Biol. Chem. 277: 3537-3543.

Gary, J.D., Lin, W.J., Yang, M.C., Herschman, H.R., and Clarke, S. 1996. The predominant protein-arginine methyltransferase from Saccharomyces cerevisiae. J. Biol. Chem. 271: 12585-12594.

Ghosh, S.K., Paik, W.K., and Kim, S. 1988. Purification and molecular identification of two protein methylases I from calf brain. Myelin basic protein- and histone-specific enzyme. J. Biol. Chem. 263: 19024-19033.

Giaever, G., Chu, A.M., Ni, L., Connelly, C., Riles, L., Veronneau, S., Dow, S., Lucau-Danila, A., Anderson, K., Andre, B., et al. 2002. Functional profiling of the Saccharomyces cerevisiae genome. $\mathrm{Na}$ ture 418: 387-391.

Girard, J.P., Lehtonen, H., Caizergues-Ferrer, M., Amalric, F., Tollervey, D., and Lapeyre, B. 1992. GAR1 is an essential small nucleolar RNP protein required for pre-rRNA processing in yeast. $E M B O J$. 11: $673-682$.

Gonzalez, C.I., Ruiz-Echevarria, M.J., Vasudevan, S., Henry, M.F., and Peltz, S.W. 2000. The yeast hnRNP-like protein Hrp1/Nab4 marks a transcript for nonsense-mediated mRNA decay. Mol. Cell 5: 489499.

Green, D.M., Marfatia, K.A., Crafton, E.B., Zhang, X., Cheng, X., and Corbett, A.H. 2002. Nab2p is required for poly(A) RNA export in Saccharomyces cerevisiae and is regulated by arginine methylation via Hmtlp. J. Biol. Chem. 277: 7752-7760.

Hebert, M.D., Shpargel, K.B., Ospina, J.K., Tucker, K.E., and Matera, A.G. 2002. Coilin methylation regulates nuclear body formation. Dev. Cell 3: 329-337.

Henriquez, R., Blobel, G., and Aris, J.P. 1990. Isolation and sequencing of NOP1. A yeast gene encoding a nucleolar protein homologous to a human autoimmune antigen. J. Biol. Chem. 265: 2209-2215.

Henry, M., Borland, C.Z., Bossie, M., and Silver, P.A. 1996. Potential RNA binding proteins in Saccharomyces cerevisiae identified as suppressors of temperature-sensitive mutations in NPL3. Genetics 142: 103-115.

Henry, M.F. and Silver, P.A. 1996. A novel methyltransferase (Hmtlp) modifies poly(A)+-RNA-binding proteins. Mol. Cell. Biol. 16: 3668-3678.

Kahana, J.A. and Silver, P.A. 1996. Use of a A. victoria green fluores- cent protein to study protein dynamics in vivo. In Current protocols in molecular biology (ed. K. Struhl), pp. 9.6.13-19.16.19. John Wiley \& Sons, New York.

Kessler, M.M., Henry, M.F., Shen, E., Zhao, J., Gross, S., Silver, P.A., and Moore, C.L. 1997. Hrp1, a sequence-specific RNA-binding protein that shuttles between the nucleus and the cytoplasm, is required for mRNA 3 '-end formation in yeast. Genes \& Dev. 11: $2545-2556$.

Kim, S., Merrill, B.M., Rajpurohit, R., Kumar, A., Stone, K.L., Papov, V.V., Schneiders, J.M., Szer, W., Wilson, S.H., Paik, W.K., et al. 1997. Identification of $\mathrm{N}(\mathrm{G})$-methylarginine residues in human heterogeneous RNP protein A1: Phe/Gly-Gly-Gly-Arg-Gly-GlyGly/Phe is a preferred recognition motif. Biochemistry 36: 51855192.

Kondo, K. and Inouye, M. 1992. Yeast NSR1 protein that has structural similarity to mammalian nucleolin is involved in pre-rRNA processing. J. Biol. Chem. 267: 16252-16258.

Lee, M.S., Henry, M., and Silver, P.A. 1996. A protein that shuttles between the nucleus and the cytoplasm is an important mediator of RNA export. Genes \& Dev. 10: 1233-1246.

Lee, W.C., Xue, Z.X., and Melese, T. 1991. The NSR1 gene encodes a protein that specifically binds nuclear localization sequences and has two RNA recognition motifs. J. Cell. Biol. 113: 1-12.

Lee, W.C., Zabetakis, D., and Melese, T. 1992. NSR1 is required for pre-rRNA processing and for the proper maintenance of steadystate levels of ribosomal subunits. Mol. Cell. Biol. 12: 3865-3871.

Lin, W.J., Gary, J.D., Yang, M.C., Clarke, S., and Herschman, H.R. 1996. The mammalian immediate-early TIS 21 protein and the leukemia-associated BTG1 protein interact with a protein-arginine N-methyltransferase. J. Biol. Chem. 271: 15034-15044.

Lischwe, M.A., Cook, R.G., Ahn, Y.S., Yeoman, L.C., and Busch, H. 1985a. Clustering of glycine and NG,NG-dimethylarginine in nucleolar protein C23. Biochemistry 24: 6025-6028.

Lischwe, M.A., Ochs, R.L., Reddy, R., Cook, R.G., Yeoman, L.C., Tan, E.M., Reichlin, M., and Busch, H. 1985b. Purification and partial characterization of a nucleolar scleroderma antigen $(\mathrm{Mr}=34,000$; pI, 8.5) rich in NG,NG-dimethylarginine. J. Biol. Chem. 260: 14304-14310.

Liu, Q. and Dreyfuss, G. 1995. In vivo and in vitro arginine methylation of RNA-binding proteins. Mol. Cell. Biol. 15: 2800-2808.

Loo, S., Laurenson, P., Foss, M., Dillin, A., Rine, J. 1995. Roles of ABF1, NPL3, and YCL54 in silencing in Saccharomyces cerevisiae. Genetics 141: 889-902.

Lubben, B., Fabrizio, P., Kastner, B., and Luhrmann, R. 1995. Isolation and characterization of the small nucleolar ribonucleoprotein particle snR30 from Saccharomyces cerevisiae. J. Biol. Chem. 270: 11549-11554.

Minvielle-Sebastia, L., Beyer, K., Krecic, A.M., Hector, R.E., Swanson, M.S., and Keller, W. 1998. Control of cleavage site selection during mRNA $3^{\prime}$ end formation by a yeast hnRNP. EMBO J. 17: 74547468.

Mowen, K.A., Tang, J., Zhu, W., Schurter, B.T., Shuai, K., Herschman, H.R., and David, M. 2001. Arginine methylation of STAT1 modulates IFN $\alpha / \beta$-induced transcription. Cell 104: 731-741.

Najbauer, J., Johnson, B.A., Young, A.L., and Aswad, DW. 1993. Peptides with sequences similar to glycine, arginine-rich motifs in proteins interacting with RNA are efficiently recognized by methyltransferase(s) modifying arginine in numerous proteins. J. Biol. Chem. 268: 10501-10509.

Nichols, R.C., Wang, X.W., Tang, J., Hamilton, B.J., High, F.A., Herschman, H.R., and Rigby, W.F. 2000. The RGG domain in hnRNP A2 affects subcellular localization. Exp. Cell. Res. 256: 522532.

Paik, W.K. and Kim, S. 1968. Protein methylase I. Purification and properties of the enzyme. J. Biol. Chem. 243: 2108-2114.

Pollack, B.P., Kotenko, S.V., He, W., Izotova, L.S., Barnoski, B.L., and Pestka, S. 1999. The human homologue of the yeast proteins Skb1 and Hsl7p interacts with Jak kinases and contains protein methyltransferase activity. J. Biol. Chem. 274: 31531-31542. 
Rho, J., Choi, S., Seong, Y.R., Cho, W.K., Kim, S.H., and Im, D.S. 2001. Prmt5, which forms distinct homo-oligomers, is a member of the protein-arginine methyltransferase family. J. Biol. Chem. 276: 11393-11401.

Rouillon, A., Surdin-Kerjan, Y., and Thomas, D. 1999. Transport of sulfonium compounds. Characterization of the s-adenosylmethionine and s-methylmethionine permeases from the yeast Saccharomyces cerevisiae. J. Biol. Chem. 274: 28096-28105.

Russell, I.D. and Tollervey, D. 1992. NOP3 is an essential yeast protein which is required for pre-rRNA processing. J. Cell. Biol. 119: 737747.

Sadler, I., Chiang, A., Kurihara, T., Rothblatt, J., Way, J., and Silver, P. 1989. A yeast gene important for protein assembly into the endoplasmic reticulum and the nucleus has homology to DnaJ, an Escherichia coli heat shock protein. J. Cell. Biol. 109: 2665-2675.

Schimmang, T., Tollervey, D., Kern, H., Frank, R., and Hurt, E.C. 1989. A yeast nucleolar protein related to mammalian fibrillarin is associated with small nucleolar RNA and is essential for viability. EMBO J. 8: 4015-4024.

Scorilas, A., Black, M.H., Talieri, M., and Diamandis, E.P. 2000. Genomic organization, physical mapping, and expression analysis of the human protein arginine methyltransferase 1 gene. Biochem. Biophys. Res. Commun. 278: 349-359.

Scott, H.S., Antonarakis, S.E., Lalioti, M.D., Rossier, C., Silver, P.A., and Henry, M.F. 1998. Identification and characterization of two putative human arginine methyltransferases (HRMT1L1 and HRMT1L2). Genomics 48: 330-340.

Shen, E.C., Henry, M.F., Weiss, V.H., Valentini, S.R., Silver, P.A., and Lee, M.S. 1998. Arginine methylation facilitates the nuclear export of hnRNP proteins. Genes \& Dev. 12: 679-691.
Shen, E.C., Stage-Zimmermann, T., Chui, P., and Silver, P.A. 2000. The yeast mRNA-binding protein Npl3p interacts with the capbinding complex. J. Biol. Chem. 275: 23718-23724.

Sikorski, R.S. and Hieter, P. 1989. A system of shuttle vectors and yeast host strains designed for efficient manipulation of DNA in Saccharomyces cerevisiae. Genetics 122: 19-27.

Singleton, D.R., Chen, S., Hitomi, M., Kumagai, C., Tartakoff, A.M. 1995. A yeast protein that bidirectionally affects nucleocytoplasmic transport. J. Cell. Sci. 108 (Pt. 1): 265-272.

Smith, J.J., Rucknagel, K.P., Schierhorn, A., Tang, J., Nemeth, A., Linder, M., Herschman, H.R., and Wahle, E. 1999. Unusual sites of arginine methylation in Poly(A)-binding protein II and in vitro methylation by protein arginine methyltransferases PRMT1 and PRMT3. J. Biol. Chem. 274: 1322913234.

Tang, J., Gary, J.D., Clarke, S., and Herschman, H.R. 1998. PRMT 3, a type I protein arginine N-methyltransferase that differs from PRMT1 in its oligomerization, subcellular localization, substrate specificity, and regulation. J. Biol. Chem. 273: 16935-16945.

Tang, J., Kao, P.N., and Herschman, H.R. 2000. Protein-arginine methyltransferase I, the predominant protein-arginine methyltransferase in cells, interacts with and is regulated by interleukin enhancer-binding factor 3. J. Biol. Chem. 275: 19866-19876.

Wilson, S.M., Datar, K.V., Paddy, M.R., Swedlow, J.R., and Swanson, M.S. 1994. Characterization of nuclear polyadenylated RNA-binding proteins in Saccharomyces cerevisiae. J. Cell. Biol. 127: 11731184.

Yun, C.Y. and Fu, X.D. 2000. Conserved SR protein kinase functions in nuclear import and its action is counteracted by arginine methylation in Saccharomyces cerevisiae. J. Cell. Biol. 150: 707-718. 

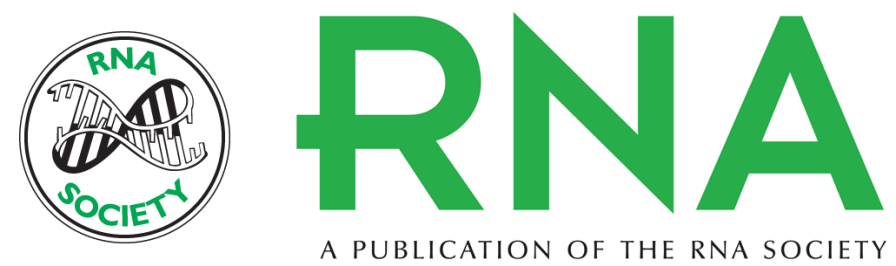

\section{In vivo analysis of nucleolar proteins modified by the yeast arginine methyltransferase Hmt1/Rmt1p}

CHONG XU, PAMELA A. HENRY, AMIT SETYA, et al.

RNA 2003 9: 746-759

References This article cites 62 articles, 42 of which can be accessed free at: http://rnajournal.cshlp.org/content/9/6/746.full.html\#ref-list-1

License

Email Alerting Receive free email alerts when new articles cite this article - sign up in the box at the Service top right corner of the article or click here. 